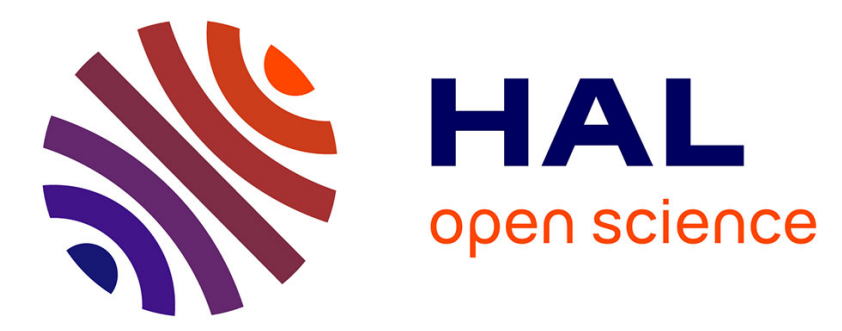

\title{
Mechanical stability of custom-made implants: Numerical study of anatomical device and low elastic Young's modulus alloy
}

\author{
Paul Didier, Boris Piotrowski, Marie Fischer, Pascal Laheurte
}

\section{To cite this version:}

Paul Didier, Boris Piotrowski, Marie Fischer, Pascal Laheurte. Mechanical stability of custom-made implants: Numerical study of anatomical device and low elastic Young's modulus alloy. Materials Science and Engineering: C, 2017, 74, pp.399-409. 10.1016/j.msec.2016.12.031 . hal-02272146

\section{HAL Id: hal-02272146 \\ https://hal.science/hal-02272146}

Submitted on 27 Aug 2019

HAL is a multi-disciplinary open access archive for the deposit and dissemination of scientific research documents, whether they are published or not. The documents may come from teaching and research institutions in France or abroad, or from public or private research centers.
L'archive ouverte pluridisciplinaire HAL, est destinée au dépôt et à la diffusion de documents scientifiques de niveau recherche, publiés ou non, émanant des établissements d'enseignement et de recherche français ou étrangers, des laboratoires publics ou privés. 


\title{
Mechanical stability of custom-made implants: Numerical study of anatomical device and low elastic Young's modulus alloy
}

\author{
P. Didier* , B. Piotrowski, M. Fischer, P. Laheurte

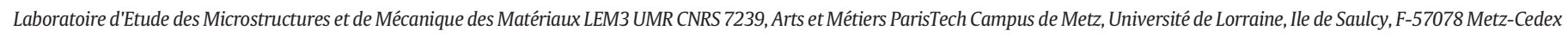 \\ 01 , France
}

\begin{abstract}
A B S T R A C T
The advent of new manufacturing technologies such as additive manufacturing deeply impacts the approach for the design of medical devices. It is now possible to design custom-made implants based on medical imaging, with complex anatomic shape, and to manufacture them.

In this study, two geometrical configurations of implant devices are studied, standard and anatomical. The comparison highlights the drawbacks of the standard configuration, which requires specific forming by plastic strain in order to be adapted to the patient's morphology and induces stress field in bones without mechanical load in the implant.

The influence of low elastic modulus of the materials on stress distribution is investigated. Two biocompatible alloys having the ability to be used with SLM additive manufacturing are considered, commercial Ti-6Al-4V and Ti$26 \mathrm{Nb}$. It is shown that beyond the geometrical aspect, mechanical compatibility between implants and bones can be significantly improved with the modulus of Ti-26Nb implants compared with the Ti-6Al-4V.
\end{abstract}

\section{Introduction}

Titanium-based alloys are widely used in the medical field for standardized implants manufacturing [1,2]. They exhibit several advantages: pure titanium $\mathrm{cp}-\mathrm{Ti}$ and titanium alloy Ti-6Al-4V have remarkable osseointegration properties [3], excellent corrosion resistance and biocompatibility [4]. Their availability allows their production and sale on a large scale. Titanium devices are used for many type of implants, such as hip endoprosthesis for structural support to replace deficient bones [5], tibia and femur titanium nails [6,7].

However, standard titanium implants have limitations. One of the most important constraints and reasons for failure is that they are not adapted to the morphology of every patient. In many cases, custommade (or anatomical) implants have shown excellent fit to the defect, reduction of the rate of implant failure, and high patient satisfaction $[2,8,9]$. Therefore, the recent developments of additive manufacturing with titanium-based alloys have significantly facilitated the fabrication of these kinds of implants $[10,11]$. This type of customized solution can be applied to a large field of traumas, as cranio-facial for bone augmentation devices [12], or mandible prosthesis [13]. Another example of limitation of standard implants (non anatomical) is the plates used to attach aesthetic epitheses on facial bones [14]. This specific case is particularly widespread with traumas resulting from face cancers, where the removal of an organ such as an eye, a nose or an ear is necessary $[15,16]$. The facial reconstruction is composed of a metallic part fixed on the bone with a screw, on which is attached an aesthetic epithesis. The standardized metallic devices have to be adapted to the morphology of the patient by the surgeon during surgery. These pieces are shaped gradually by successive plastic deformations in order to embrace as best as possible the bone shape on which they will be fixed [17]. This step, named contouring, extends the duration of the operation and the cumulative plasticity weakens the piece; it is requested to avoid it [9]. Moreover, even after classical contouring on standard plates, the shape of the implant cannot perfectly match the physiological topology of the bone. This induces that the surgeon has to force to adapt the piece on the bone before screwing the two parts together. Thus, without any load condition on the implant, it is, once screwed, subject to stresses.

One other cause of implant failure is the mismatch in modulus of elasticity between bone and implant. That induces stress-shielding effect $[4,18]$. It has already been demonstrated that the application of a load on metallic rigid device implanted in a bone induces stress shielding, resulting in unloading of some areas and overloading others $[19,20]$. This phenomenon is all the more significant when the implant is rigid, and titanium-based alloys such as Ti-6Al-4V exhibit a relatively high Young's modulus (110 GPa) [21]. In the last few years, new beta-titanium alloys have been developed with the particularity to present an elastic modulus notably inferior to that of Ti-6Al-4V. Indeed, after a specific thermo-mechanical treatment, Ti-XNb alloys reach a low young modulus up to $30 \mathrm{GPa}$ [22]. Implants made with this type of material 


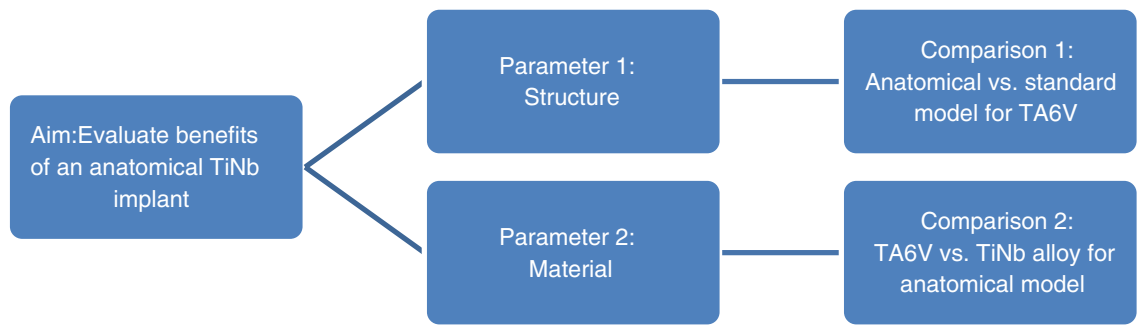

Fig. 1. Schematic representation of the study strategy.

have better mechanical stability, on the one hand by reducing the stress shielding in the bone compared to a physiological situation, and on the other hand by minimizing the stress gap between the implant and the bone responsible for micro movements [23-25]. Moreover, a lot of studies highlight the excellent biocompatibility of this type of materials, beyond cytotoxicity and corrosion tests [26-31]. In addition to all these advantages, a key point is that Ti-XNb alloys are suitable to additive manufacturing technology [32].

To investigate the implant-bone mechanical behavior, several approaches can be employed. In this work, finite elements method is adopted. Many finite element studies have already been proposed to explore bone-implant interface, revealing the benefits of the adapted structure of implants [10], or the advantages of low Young's modulus alloy [23]. The specific scope of dental field is particularly investigated [33-35]. Some studies take into account some surgical aspects of implants fixing by finite element methods [36,37]. However, few papers take into considerations both effects of structural and material optimization.

The aim of this study is to highlight the combined influence of low elastic modulus (material) and anatomical shape (structure) on the mechanical stability of an implant. In the first part of this work, we propose to describe the setting up of the finite element models composed with three simplified parts (screw, bone and implant) used to respond to the presented problem. At the same time, we will present the mechanical properties of the two materials Ti-6Al-4V and Ti-26Nb. In the second part, results for quantifying the advantages of custom-made or anatomical implants in comparison to the use of a standardized implant are presented and commentated.

\section{Materials and methods}

\subsection{Anatomical and standard implant finite element models}

The study appreciates the benefits of an anatomical implant in Ti26Nbin observing what happened (i) when firstly a surgeon establishes and screws an implant on the skull; (ii) when secondly a displacement is applied on this implant. Thus two parameters are studied. The first one is the global shape of the implant, considering an anatomical or a standard implant. The second one is the stiffness of the material, depending on whether the implant is made ofTi-6Al-4V or Ti-26Nb
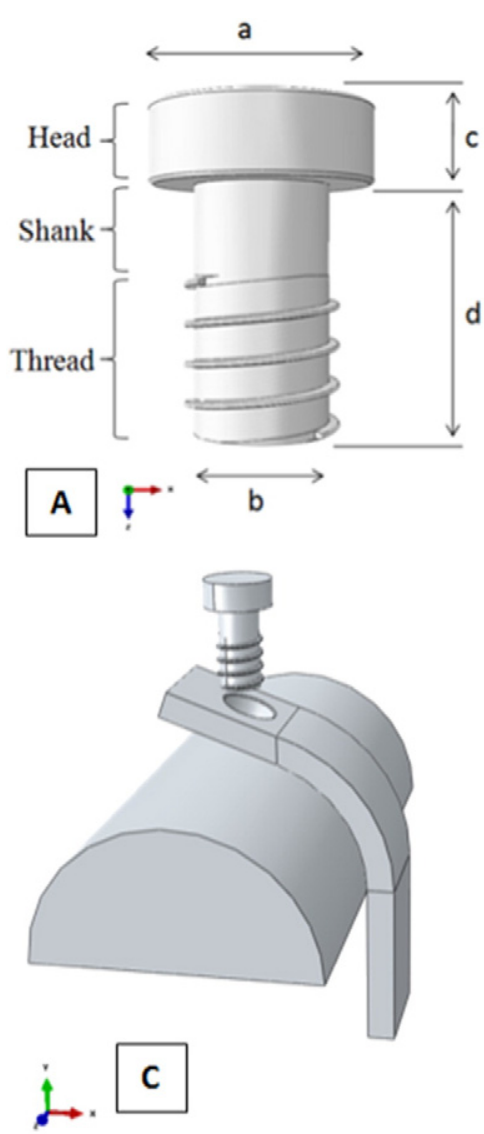
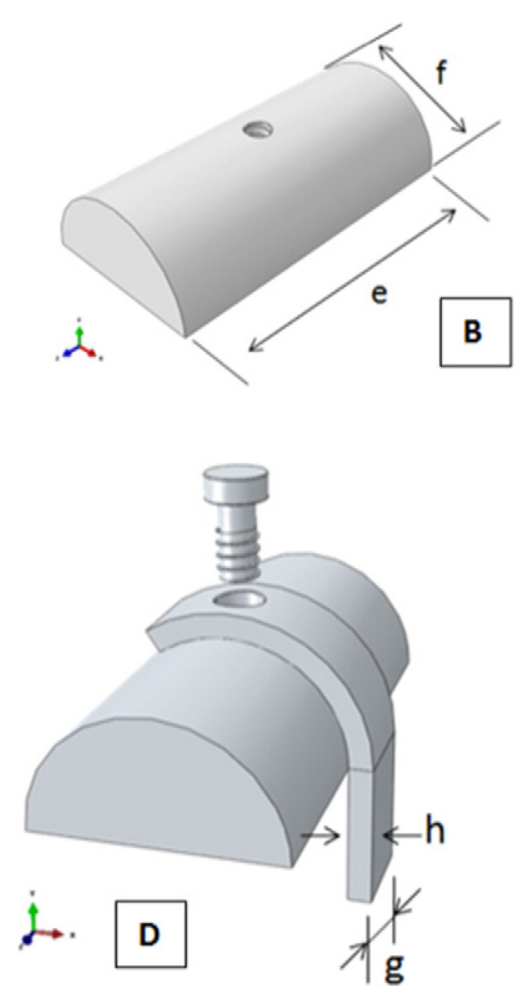

\begin{tabular}{|c|c|}
\hline $\mathrm{a}$ & $\varnothing 2.5 \mathrm{~mm}$ \\
\hline $\mathrm{b}$ & $\varnothing 1.5 \mathrm{~mm}$ \\
\hline $\mathrm{c}$ & $1.0 \mathrm{~mm}$ \\
\hline $\mathrm{d}$ & $3.0 \mathrm{~mm}$ \\
\hline $\mathrm{e}$ & $20.0 \mathrm{~mm}$ \\
\hline $\mathrm{f}$ & $\varnothing 10.0 \mathrm{~mm}$ \\
\hline $\mathrm{g}$ & $4.0 \mathrm{~mm}$ \\
\hline $\mathrm{h}$ & $1.0 \mathrm{~mm}$ \\
\hline
\end{tabular}

Fig. 2. Geometrical characteristics of the considered entities: the screw (A), the bone part (B), the entire standard model (C) and the entire anatomical model (D), 

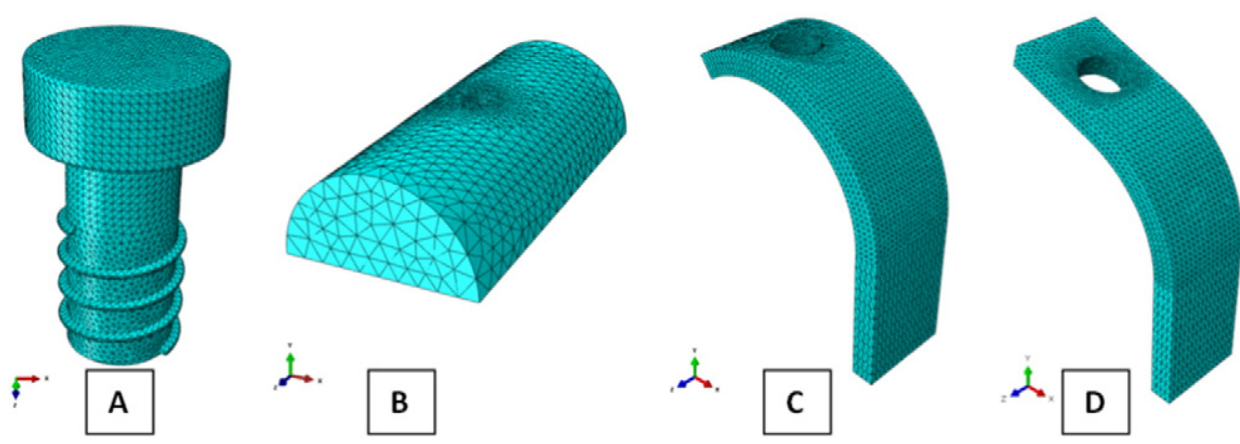

Fig. 3. Mesh representation of the considered parts of the two models: the screw (A), the bone part (B), the anatomical implant (C) and the standard implant (D).

biocompatible alloy. This induced two comparisons: anatomical Ti-6Al$4 \mathrm{~V}$ versus standard Ti-6Al-4V, and anatomical Ti-6Al-4V versus anatomical Ti-26Nb. Thus two main finite element models are considered (standard and anatomical), with a possible changing material. A synthetic diagram of the study strategy is presented in Fig. 1. The different mechanical characteristics of the materials (Ti-6Al-4V, Ti-26Nb, cortical bone) used in the models are presented in Section 2.2 Identification of material properties.

\subsubsection{Geometrical characteristics}

Three entities are necessary to build the models: a screw, a piece of a skull and an implant. The screw and the bone parts are exactly the same in the two finite element models.

Concerning the bone part, a simplified model is considered in order to avoid parasite effects. Indeed, the important feature is the curvature and the no-plate topography of the skull bone, so the bone is modeled by a semi-cylinder. The dimensions are shown in Fig. 2.

The screw is composed of three areas, on the one hand the head, on the other hand a threaded part in contact with the bone and a smooth part in contact with the implant (the shank). The geometry characteristics are presented in Fig. 2.

The difference between these two models is due to the geometry of the perforated extremity of the implant. It is assumed that this portion is deformed by the surgeon in the standard case when he sets the screw, but not deformed in an anatomical case, because of the adapted shape of the anatomical implant. To approach the real case, the central part of the implant is fitted to the bone in both cases. It simulates the fact that a surgeon firstly deforms the implant with pliers for maximal adjustment of the implant shape to the skull shape.

So in the anatomical model, the implant has exactly the same curvature as the bone. And in the standard model, the extremity with the hole is linear and does not bond to the bone. In the two simulations, the implant is $4 \mathrm{~mm}$ wide and $1 \mathrm{~mm}$ thick, as showed in Fig. 2 .

\subsubsection{Mesh}

All parts were meshed with C3D10 tetrahedron elements with quadratic interpolation, as illustrated in Fig. 3.

In order to define the size of the elements, a preliminary convergence analysis was performed. The implant was meshed with a maximum size of $0.5 \mathrm{~mm}$ with a progressive decrease around the hole down to $0.1 \mathrm{~mm}$. The bone was also meshed with progressive discretization from $1 \mathrm{~mm}$ at the borders to $0.1 \mathrm{~mm}$ around the threaded hole of the screw. The screw was entirely meshed with $0.1 \mathrm{~mm}$ sized elements. The number of elements were respectively $44,711,52,575$,

Table 1

Interaction strategy between the different contact pairs of the finite element models, namely bone-screw, implant-screw and implant-bone.

\begin{tabular}{llll}
\hline Interaction & Bone-screw & Implant-screw & Implant-bone \\
\hline Type & Merge & Contact without friction & Contact without friction \\
\hline
\end{tabular}

62,365 and 70,763 for the standard implant, the anatomical implant, the bone and the screw.

\subsubsection{Interactions between components}

The bone and the screw were merged together to simplify the contact between them, because of the complexity of the threaded geometry. The merge operation has the advantage of still allowing the assignation of different materials to different partitions and the contact is assumed to be perfect.

A simple contact without friction for the other interactions was applied, namely between the inferior surface of the implant and the bone, the internal surface of the implant's hole and the screw's shank, and the superior surface of the implant and the screw's head. Previous tests with various friction penalties ( 0.1 and 0.5 ) were carried out to justify the frictionless behavior, and it appears that the results are uniform and identical regardless of the friction penalty. The different interaction properties are summarized in Table 1 .

\subsubsection{Successive steps of the numerical models}

Different geometries induce different model constructions, but it is necessary to compare their performance. This justifies a similar loading condition applied to each model from a geometrically similar situation. Consequently, preliminary calculation steps are needed in the standard case in order to implement this similar initial condition.

In the anatomical case, the surgeon just has to place the implant at the surface of the bone and screw it without any deformation of the implant. This is the main interest of an anatomic implant. The only loading ever applied on the metallic implant is the daily positioning and removal of the epithesis. The epithesis not being considered in the models, these actions are modeled with a displacement imposed on the implant,

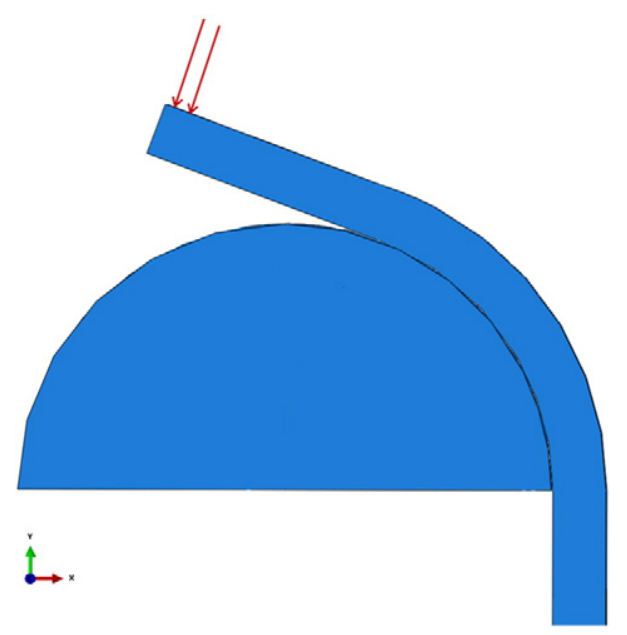

Fig. 4. Location of the pressure load in the standard finite element model, to induce forming of the implant. 


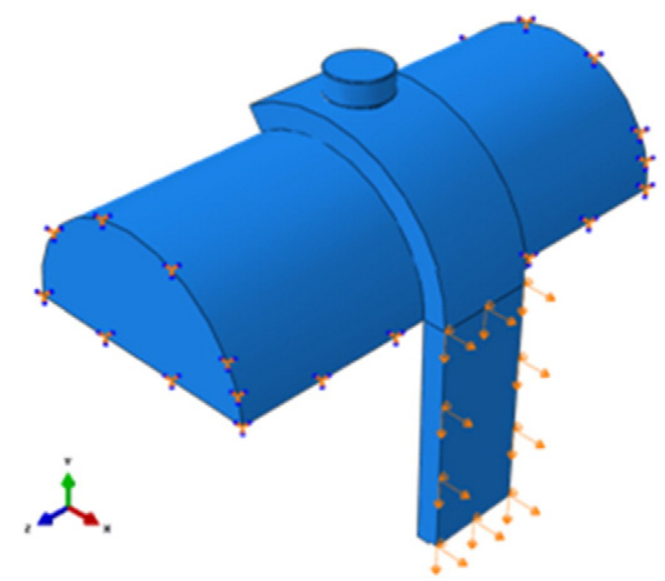

\section{Encastre}

\section{$\triangle$ Displacement}

Fig. 5. Load applied and boundary conditions locations.

Table 2

Decomposition of the applied displacement according to the different models and the several successive steps.

\begin{tabular}{|c|c|c|c|}
\hline & Initiated displacement & Shear displacement & Total \\
\hline Standard model & $0.22 \vec{x}$ & $0.1 \vec{x} ;-0.1 \vec{y}$ & $0.32 \vec{x} ;-0.1 \vec{y}$ \\
\hline Anatomical model & $0.25 \vec{x}$ & $0.1 \vec{x} ;-0.1 \vec{y}$ & $0.35 \vec{x} ;-0.1 \vec{y}$ \\
\hline
\end{tabular}

referred to as epithesis loading. Thus the simulation is only composed of the final loading of the implant, the screw being placed at the beginning of this study.

In the standard case, contrary to the anatomical case, it is not possible to place and directly screw the implant on the bone, because it simply does not fit. Therefore the surgeon deforms the implant when he screws it, and forces it to adapt its shape to the bone, as explained previously. To simplify this stage, this first simulation is separated into several steps:

- Application of a pressure at the top of the holed extremity of the implant in order to deform it, shown in Fig. 4;

- Placing of the screw;

- Unloading of the pressure, which induces by elastic return a contact between implant and head of screw; hence the device is considered in the initial state for the application of the epithesis loading;

- Application of the epithesis loading.
The load is applied at the extremity of the implant and is equivalent to a force of $195.2 \mathrm{~N}$, which is the minimum force for a necessary deformation of the implant for the placing of the screw.

\subsubsection{Load and boundary conditions}

Once the preliminary steps are achieved, similar loads and boundary conditions can be applied. Boundary conditions are the same in the two models. However the epithesis loading is slightly different, modeled with a displacement applied to the implant.

First of all, the bone is always fixed through 3 surfaces.

The other condition, the epithesis loading, is applied on the inferior extremity of the implant. The locations of these two conditions are presented in Fig. 5. It can be composed of 2 stages: firstly, the implant is moved in the $\mathrm{x}$ axis direction until contact between the implant and the screw's shank, in order to reduce the slack between the screw and

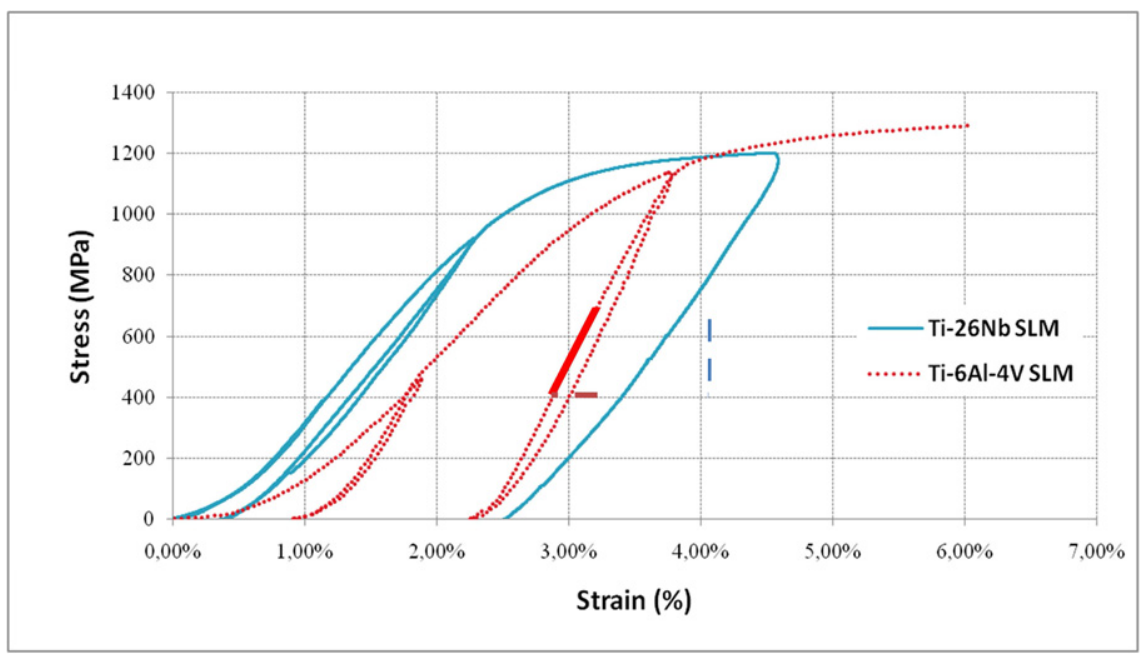

Fig. 6. Stress-strain curves of the compression tests of the Ti-6Al-4V (solid curve) and Ti-26Nb (dotted curve), with two loading cycles of each alloy. 
Table 3

Mechanical elastic properties of the different materials used for the finite element models.

\begin{tabular}{ll}
\hline Materials & Young's modulus (GPa) \\
\hline Ti-6Al-4V & 110 \\
Ti-26Nb & 60 \\
Cortical bone & 15
\end{tabular}

the implant. This first displacement is not exactly the same in the two cases because of the previous plastic deformation of the implant in the standard model. Indeed, the implant hole's border is not at the same distance from the screw shank in these models. When the contact is initiated between the screw and the implant, another displacement which is identical in each case, in $\mathrm{x}$ and $\mathrm{y}$ axis, is applied to pull on the screw.

The adopted displacement imposed for epithesis loading was selected arbitrarily. Thus, the resulting values are not necessarily physiological, but allow comparison between cases. They are recapitulated in Table 2.

All the models were made with Abaqus 6.13 (Dassault), and all the simulations were performed with nodes of $16 \mathrm{CPU}$. The calculation times for a standard case and an anatomical case were respectively $5 \mathrm{~h}$ and $3 \mathrm{~h}$.

\subsection{Identification of material properties}

In the present study, for the metallic parts (screw and implant), two materials have been considered: Ti-6Al-4V and Ti-26Nb both processed by Selective Laser Melting (SLM). Material properties were obtained experimentally with uniaxial compression tests on parallelepiped samples elaborated with a SLM280HL machine (SLM Solutions). These characterization tests are required because there are no compression curves of these alloys elaborated by SLM in literature. The Fig. 6 shows that the Young's Modulus measured for Ti-6Al-4V and for Ti-26Nb were respectively $110 \mathrm{GPa}$ and $60 \mathrm{GPa}$. Very close plastic behaviors can be observed between the two alloys. Hence, for both materials, the same isotropic plastic behavior has been adopted and only the Young's modulus was changed, in order to focus on the stiffness influence. Thus a typical Ti-6Al-4V plastic behavior is adopted for both alloys [38].

For the modeling of the bone, cortical bone, an elastic modulus of 15 GPa was considered [39,40], neglecting cancellous bone. This choice of definition was retained principally because in practice the screw mainly penetrates the cortical bone. Moreover, it is well known that the cortical bone stiffness is around 10 times greater than that of cancellous bone [41]. The materials elastic properties are summed up in Table 3.
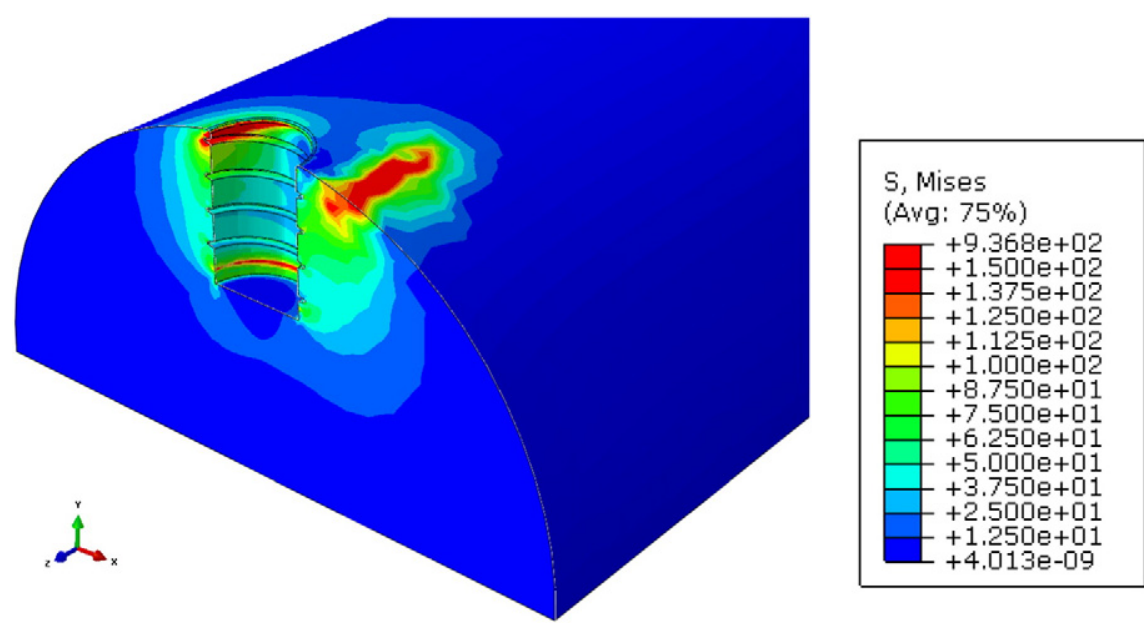

Fig. 7. Von Mises stress distribution in the standard case, after forming the implant, before the application of the displacement.
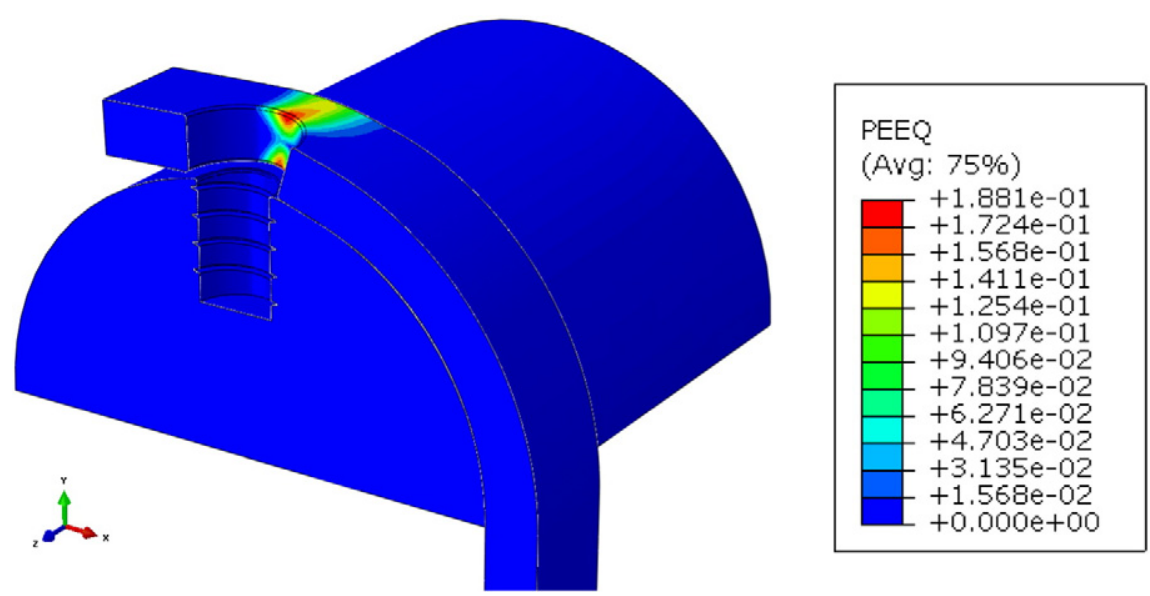

Fig. 8. Plastic equivalent strain in the implant, after its deformation, before the application of the displacement. 


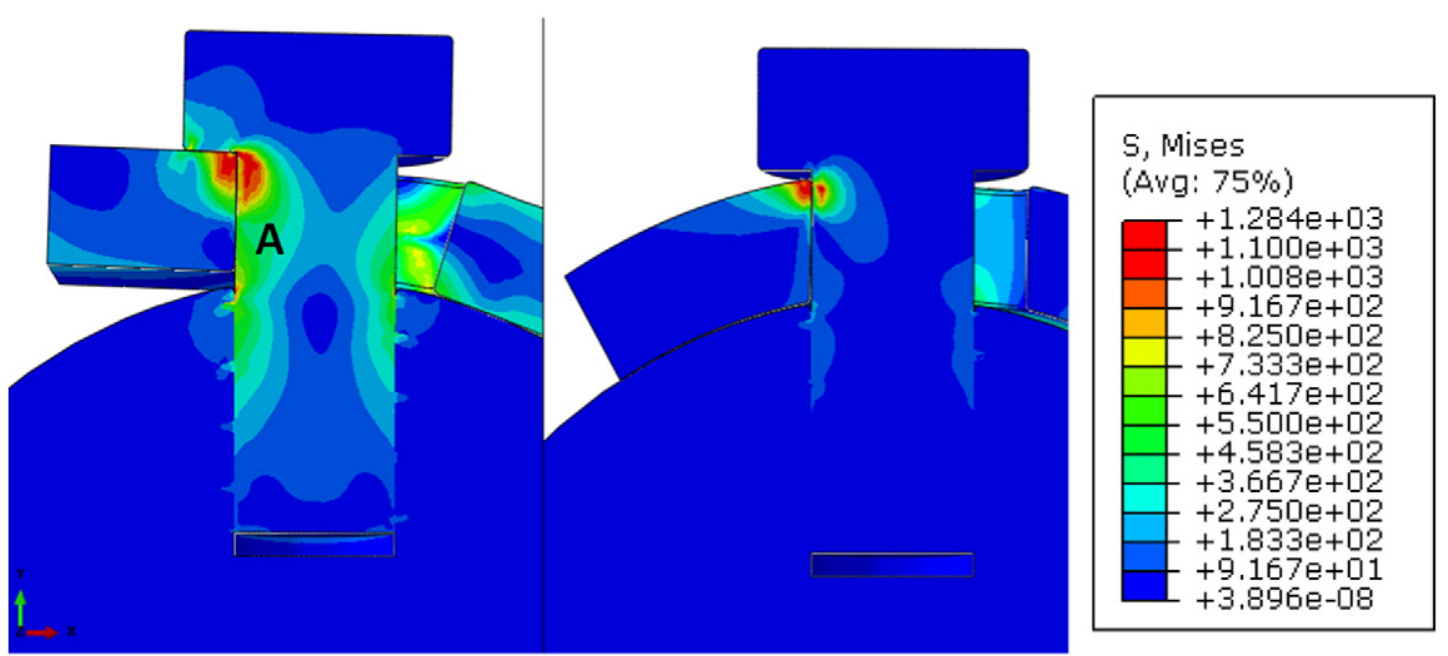

Fig. 9. Comparison of the general stress fields of the standard model (left) and the anatomical model (right).

\section{Results and discussion}

Four kinds of results have been retained to compare the different cases:

- The residual stresses in the bone in the standard case due to the deformation of the implant before the application of the solicitation;

- The general stress fields in different parts in the two models, especially the stress shielding in the bone;

- The shear stress field along the screw;

- The stress gap between the bone and the screw along the interface of the hole.

The symmetry plane, normal to the $z$ axis, was chosen to observe the different results, in order to have a global view in all parts of the field outputs.

As mentioned in the previous section, the load applied to the systems has been chosen arbitrarily. Hence, the relative data highlighting advantages of configurations compared to others are investigated.

\subsection{Residual stresses in the bone in the standard model}

In this section, the residual stresses in the bone due to contact pressure of the forming of the implant are observed. Once the standard implant is screwed on the bone, even before the solicitation is applied to the model, an important stress field can be observed mostly in the bone as illustrated in Fig. 7. In the anatomical framework, the implant is already shaped to correspond to the bone's surface. Therefore this type of implant does not need any preliminary deformation and the bone is not solicited.

The Von Mises stress field in the bone and the plastic equivalent strain in the implant are investigated, and presented in Figs.s 7 and 8. After the deformation of this implant and the placing of the screw, which retains its elastic return despite a plastic deformation, a high level of Von Mises stresses can be observed in the skull part. Two main areas are identified, where the stresses are concentrated and exceed $150 \mathrm{MPa}$. Firstly the bone is compressed by the implant on the right side of the threaded hole. On the other hand, the relaxation of the pressure on the extremity of the implant after the establishment of the screw creates another resulting pressure on the inferior left side

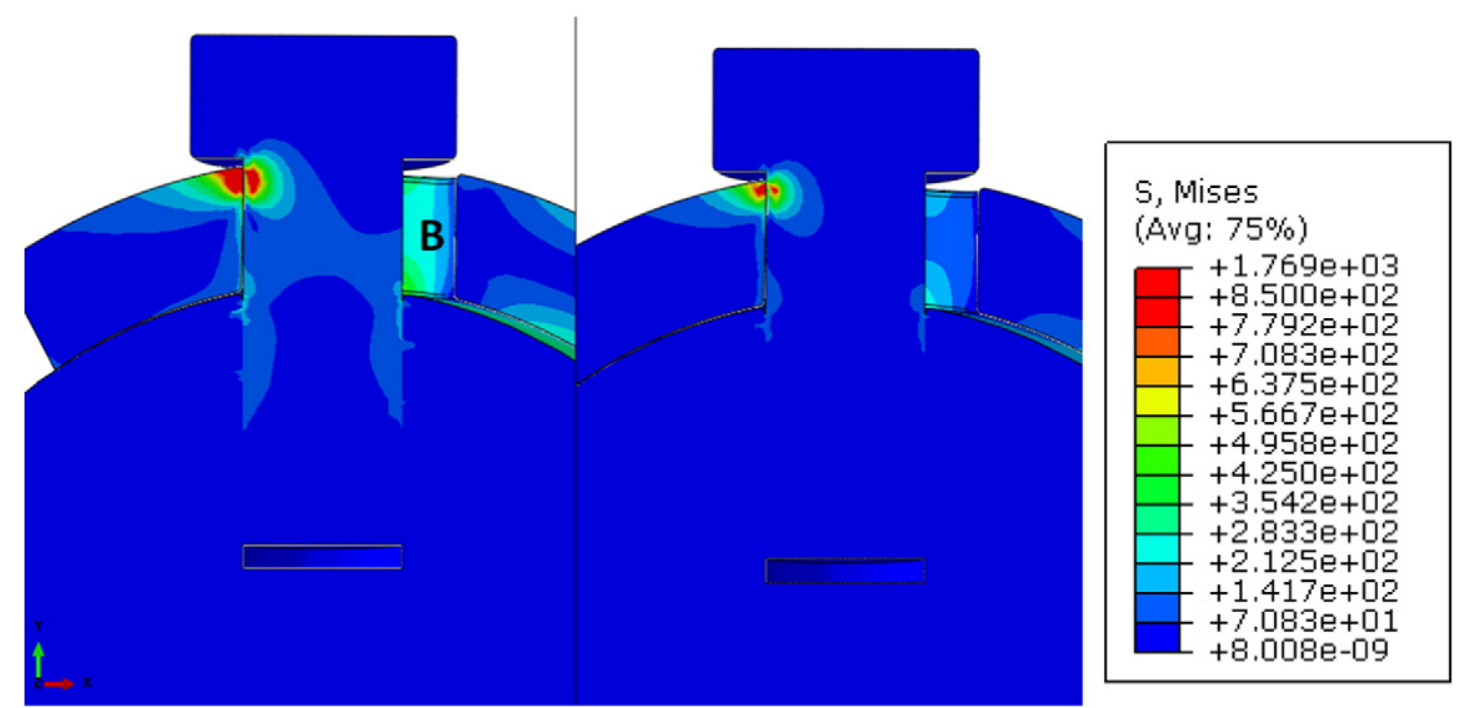

Fig. 10. Comparison of the general stress fields of the anatomical model with Ti-6Al-4 V (left) and Ti-26Nb (right). 


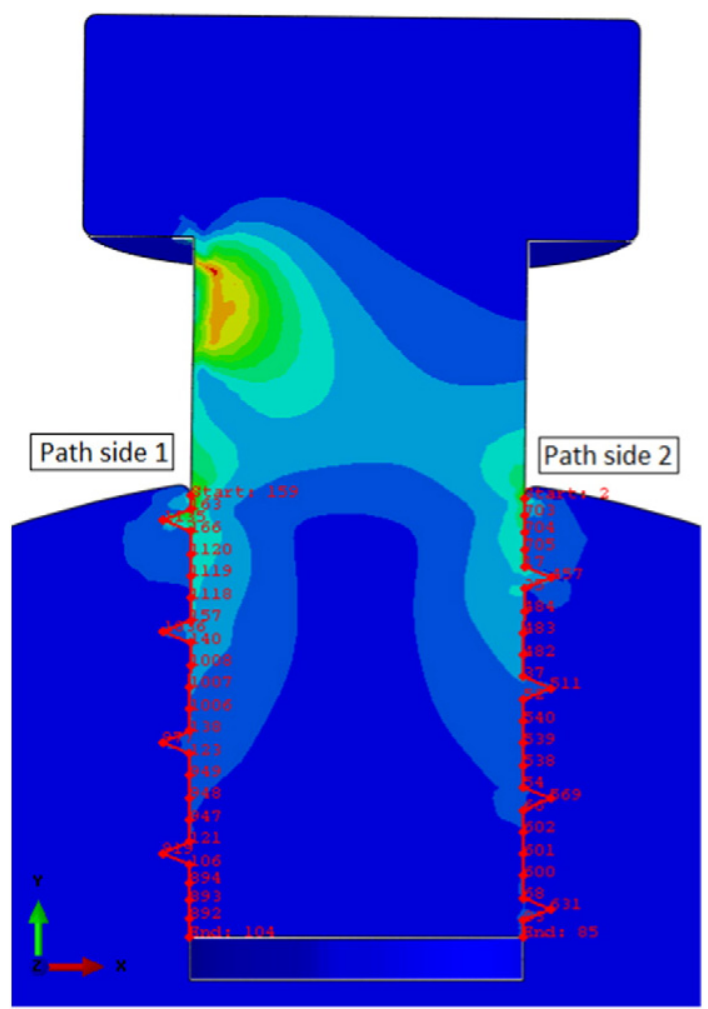

Fig. 11. Location of the two paths used along the screw-bone interface.

of the screw's head. This resulting pressure involves a concentration of stresses on the left side of the top of the hole.

These residual stresses have two misgivings. Firstly, they could induce bone densification in unsuitable areas, and also deeply impact the physiological state. Under loading of these bones, stress shielding can induce unloaded areas, which can be responsible for osteoporosis. The second point is the admissible additional stress. It can be seen that the stress field is around $150 \mathrm{MPa}$ in bone. With a plastic yield stress between 150 and $200 \mathrm{MPa}$, this means that this bone cannot accept additional stress.

\subsection{General Von Mises stress fields}

Before analyzing the results in specific areas, it is important to have an overview of the whole frameworks. The Von Mises stress field in the same cutting plane as previously is also studied as illustrated in Figs.s 9 and 10 .

Concerning the first comparison, which highlights the importance of an adapted geometry, Fig. 8 shows that a higher stress concentration can be observed in each part of the standard model despite a similar displacement initially applied, especially in the screw. It can be seen that in the standard case, the screw part in contact with implant (area A) reaches around $550 \mathrm{MPa}$, whereas it does not exceed $200 \mathrm{MPa}$ in the anatomical case.

In the second study, where the influence of the material is tested, Fig. 9 reveals that the difference in stress repartition is less important. Nonetheless, the use of Ti-26Nb implant reduces the Von Mises stresses in every part. For instance, the Von Mises stress in the internal surface of the implant's hole (area B) is around $350 \mathrm{MPa}$ for the Ti-6Al-4V alloy and less than $200 \mathrm{MPa}$ for the Ti-26Nb alloy.

The Von Mises stresses in the bone where the concentration is the highest, at the interface with the screw, is particularly investigated. The solicitations in the bone are the most important because the bone should be the latest to be damaged. To do so, two paths on each side of the screw following nodes along the hole were used, presented in Fig. 11. For each node, the Von Mises stresses were picked for comparisons between models. The distribution being very similar on each side with the same values, it has been decided to just focus on side 1 .

Firstly, concerning the influence of geometry, Fig. 12 highlights the fact that there are less solicitations in the bone all along the areas of interest in the anatomical case. On average, the diminution reaches $72 \%$ (Table 4). This is mainly explained by initial stress state in the bone due to geometric incompatibilities (before loading) and by a better stress repartition. Thus, replacing a standard implant by a custom one is less traumatic for the bone.

Then, the anatomical case is compared to the same model with low Young modulus Ti-26Nb instead of Ti-6Al-4V. Again, the distribution of Von Mises stresses along the path shows an average decrease by $34 \%$, so it can be concluded that the influence of material is significant. Finally, the Von Mises stress field in the bone is reduced by $81 \%$ with the use of a Ti-26Nb custom implant.

\subsection{Stress gap between the bone and the screw}

The observation of solicitations in the bone is a key to highlight the influence of studied parameters. However, the appreciation of the stress gap between the screw and the bone, responsible for micro-movements inducing a loss of implant stability, can be more effective. Along the contact surface between the screw and the bone, the same paths of nodes presented in Fig. 10 have been defined in the post-treatment files. The stress gap is calculated on each common node between the screw and the bone, thanks to

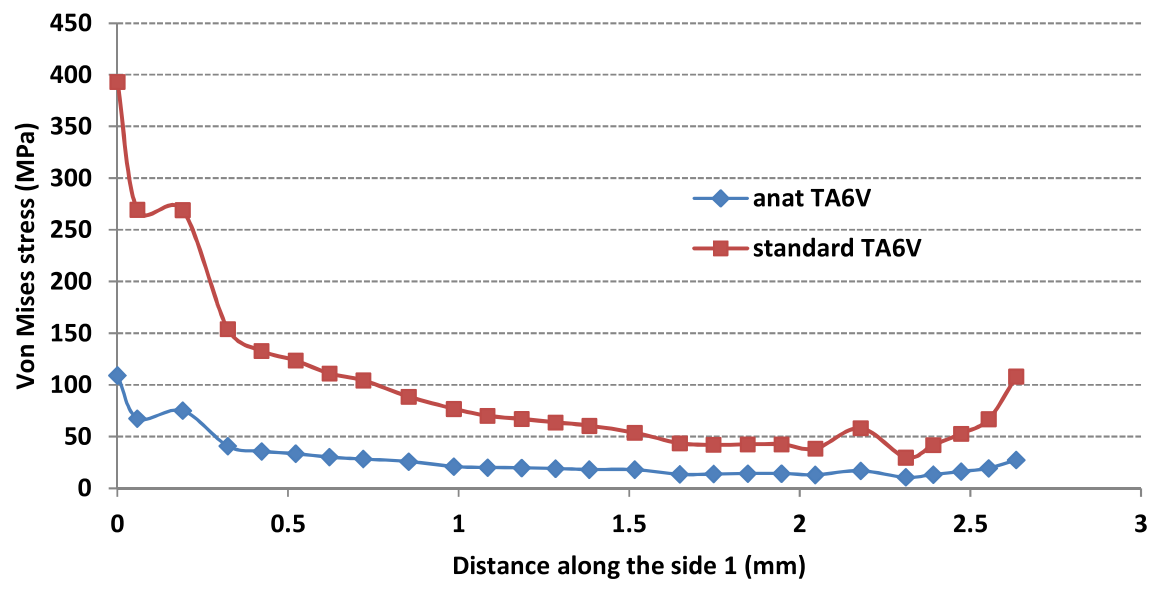

Fig. 12. Representation of the Von Mises stresses along the side 1 comparing the anatomical and standard model in Ti-6Al-4V. 
Table 4

Results of the average decrease of the Von Mises stresses on the two sides of the screw-bone interface, according the different comparisons.

\begin{tabular}{|c|c|c|c|}
\hline Average decrease of the Von Mises stress in the bone & $\begin{array}{l}\text { Standard Ti-6Al-4V vs. anatomical } \\
\text { Ti-6Al-4V }\end{array}$ & $\begin{array}{l}\text { Anatomical Ti-6Al-4V vs. anatomical } \\
\text { Ti-26Nb }\end{array}$ & $\begin{array}{l}\text { Total: standard Ti-6Al-4V vs. anatomical } \\
\text { Ti-26Nb }\end{array}$ \\
\hline Side 1 & $72 \%$ & $34 \%$ & $81 \%$ \\
\hline Side 2 & $64 \%$ & $34 \%$ & $76 \%$ \\
\hline
\end{tabular}

the merge operation between the two components during the design of the models. The evolution of the stress gap along the path is represented in Fig. 13. The evolution being very similar on each side with the same aspect, results on side 1 are presented.

The screw threads can be recognized because of the successive rough decreases on the chart Fig. 14; therefore the most solicited areas are between the threads. When the geometry parameter is changed in the anatomical case, the stress gap of Von Mises stress is significantly reduced, especially between the threads. For example on the second threads, the gap exceeding $300 \mathrm{MPa}$ in the standard case decreases less than $100 \mathrm{MPa}$ in the custom case. Table 5 shows that the results of the Von Mises stress gap on both sides, in terms of average, are almost the same. The decrease reaches $73 \%$ on side 1 and $71 \%$ on side 2 . The value is slightly different but the case is not symmetric. Indeed, the direction of the applied load is more favorable for side 1 .
Secondly, when the material influence is investigated by comparison between Ti-6Al-4V and Ti-26Nb, a significant diminution can also be observed all along the sides. In fact, in the custom low modulus model, the stress jump does not even exceed $25 \mathrm{MPa}$ along the entire interface, except for the first point. Respective average diminutions of $61 \%$ and $60 \%$ are noted for side 1 and 2 with this second comparison, which are almost as high as the first comparison. These results are explained by the screw and the implant's low Young's modulus, which comes close to the bone Young's modulus. This is an important result because it demonstrates that the stress-shielding in bone due to a load in the implant is minimized with a Ti-26Nb custom device, which ensures a better stability of implant.

Finally the stress jump is reduced by $90 \%$ and $89 \%$ when the two changing parameters are considered. This emphasizes the interest of these two possible improvements.

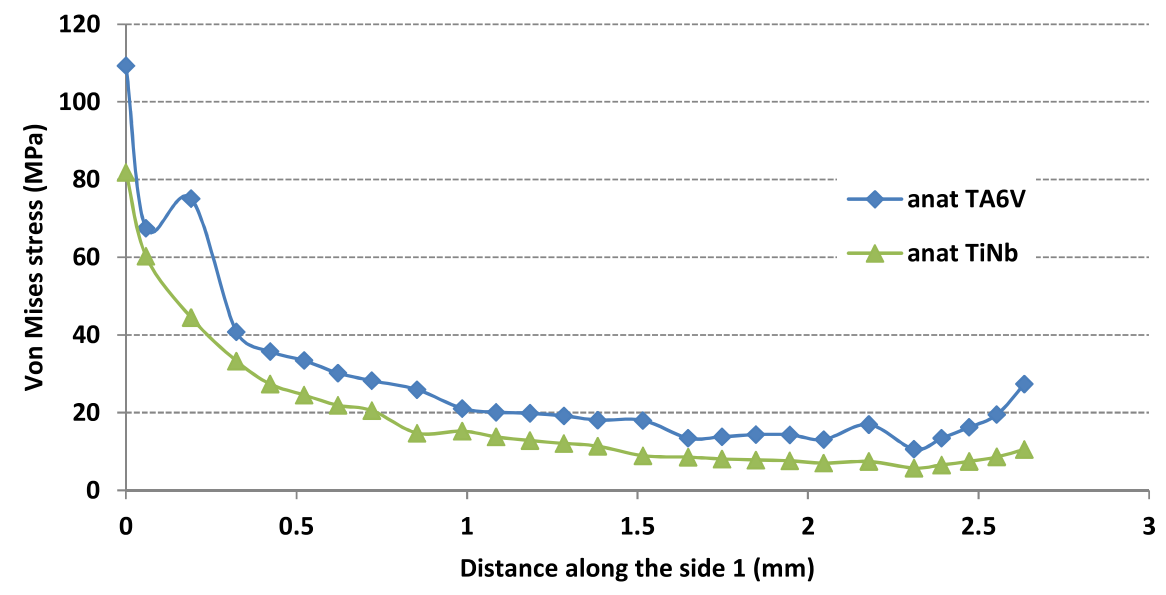

Fig. 13. Representation of the Von Mises stresses along the side 1 comparing the anatomical model in Ti-6Al-4V and Ti-26Nb.

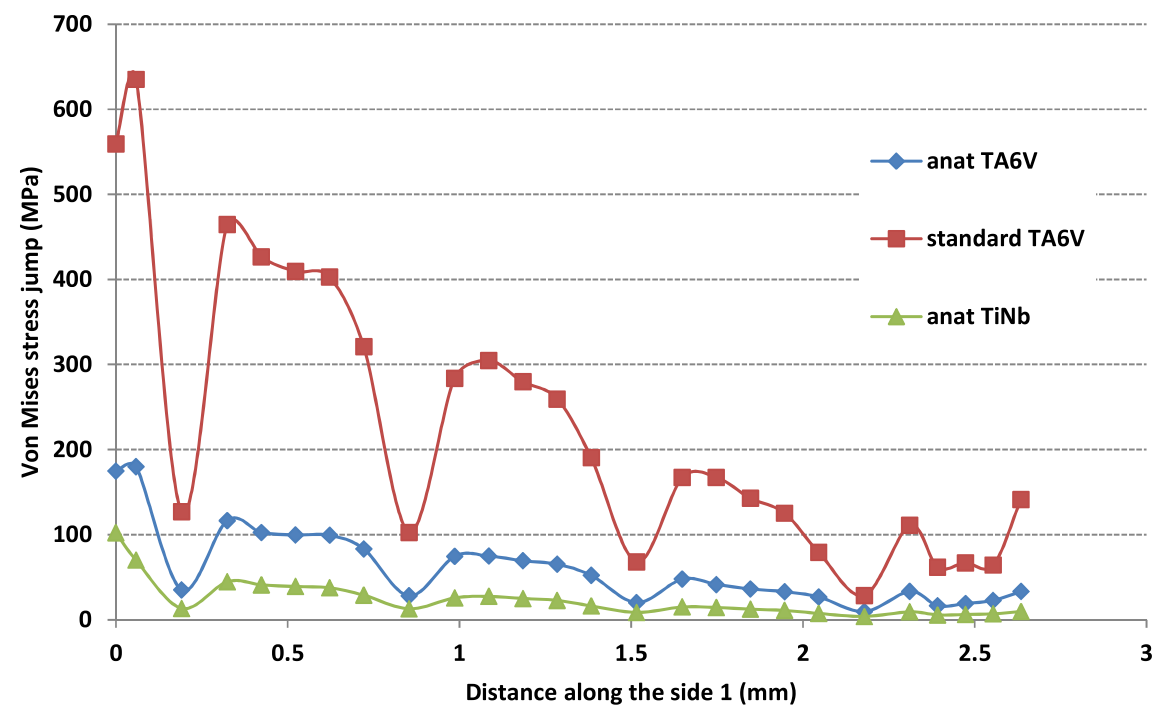

Fig. 14. Representation of the Von Mises stress gap between the screw and the bone, along the side 1, according to different model configurations. 
Table 5

Results of the average decrease of the Von Mises stress gap between the screw and the bone on both sides, according to different comparisons.

\begin{tabular}{|c|c|c|c|}
\hline $\begin{array}{l}\text { Average diminution of the Von Mises stress jump } \\
\text { between the screw and the bone }\end{array}$ & $\begin{array}{l}\text { Standard Ti-6Al-4V } \\
\text { vs. anatomical Ti-6Al-4V }\end{array}$ & $\begin{array}{l}\text { Anatomical Ti-6Al-4V } \\
\text { vs. anatomical Ti-26Nb }\end{array}$ & $\begin{array}{l}\text { Total: standard Ti-6Al-4V } \\
\text { vs. anatomical Ti-26Nb }\end{array}$ \\
\hline Side 1 & $73 \%$ & $61 \%$ & $90 \%$ \\
\hline Side 2 & $71 \%$ & $60 \%$ & $89 \%$ \\
\hline
\end{tabular}
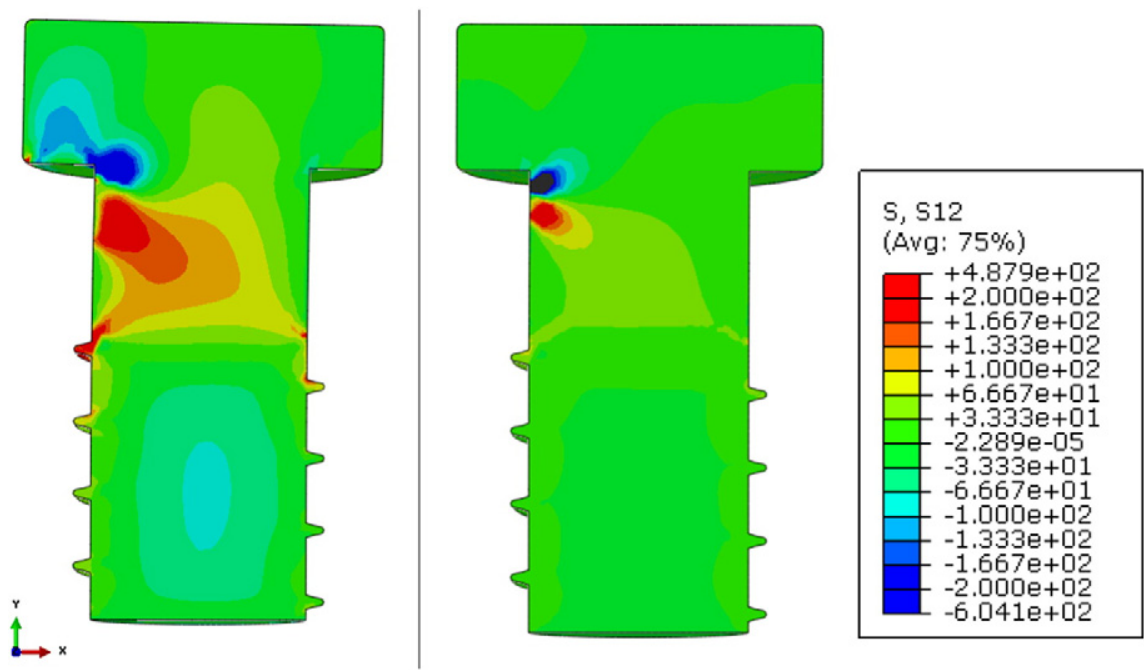

Fig. 15. Comparison of the general shear XY stress fields in the standard model (left) and in the anatomical model (right) in Ti-6Al-4V.

\subsection{Shear stresses in the screw}

Interest was set in the shear stress field $\left(\sigma_{\mathrm{xy}}\right)$ in the same symmetry plane as previously, to consider the stability of the screw. The shear XY
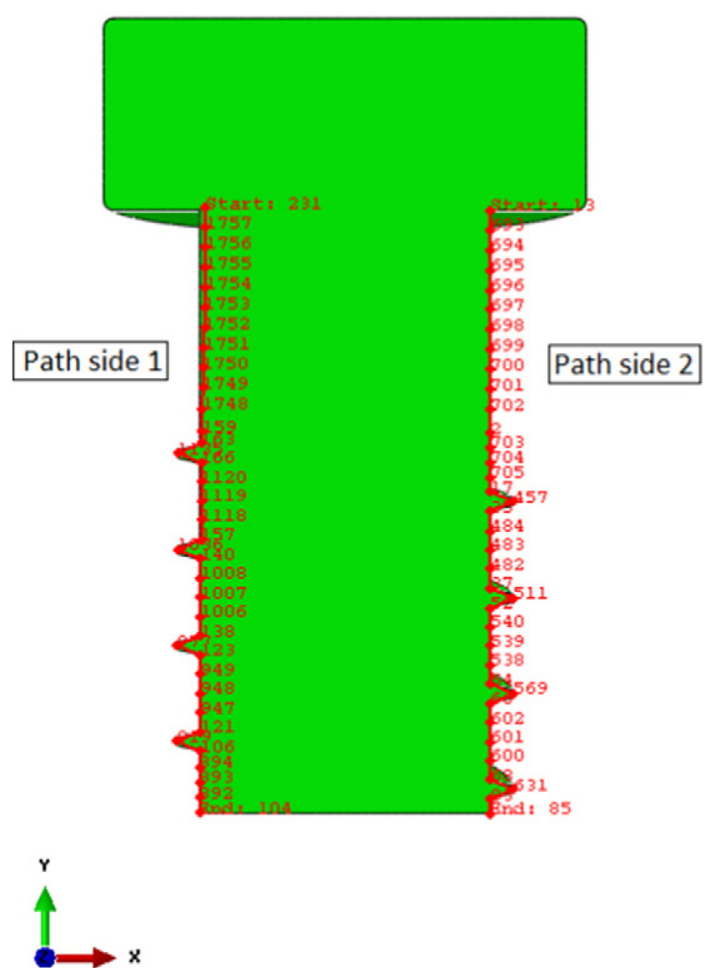

Fig. 16. Location of the two paths used to capture the XY shear stresses along the screw. component stress is investigated because it is the most important in the global Cauchy stress tensor.

The general shear stress field in the screw was observed with the first comparison concerning the adaptive geometry, in order to have an overview of the repartition of shear stresses in the screw. Even if the maximum values reach $600 \mathrm{MPa}$ in absolute value in the two cases, the shear stresses are less important and extended in the anatomical case, as showed in Fig. 15.

To quantify our expectations, paths have been defined on the borders of the screw, showed in Fig. 16.

Figs. 17 and 18 represent shear stress evolution along these two different paths on the screw. On side 1, the screw is impacted by the implant which shears it because of the displacement imposed. It is different on side 2, where the screw is in contact with the bone. This explains the different distribution of shear stresses along both sides.

Despite different distributions, the same tendency can be observed: when the implant geometry is changed, the stresses significantly decrease, mostly on the first half of the paths. On average, the diminution is $69 \%$ on the first side and $74 \%$ on the second side, as can be seen on Table 6.

The replacement of Ti-6Al-4V with Ti-26Nb induces a less significant decrease in shear stress, which is however not negligible. All along the paths, Ti-26Nb stresses are below Ti-6Al-4V stresses and are weaker by $44 \%$ on side 1 and $49 \%$ on side 2 . With the two cumulated improvements, a benefit of $83 \%$ and $87 \%$ are obtained on side 1 and 2 , respectively. Thus, the principal solicitation of the screw being a shear solicitation, it can be concluded that an anatomical implant in Ti-26Nb widely contributes to the sustainability of the screw.

\section{Conclusion}

Custom-made Ti-26Nb implants, including the combined effects of low modulus and anatomical shape, provide better mechanical stability compared with Ti-6Al-4V plate usually implanted, especially with surrounding bones. 


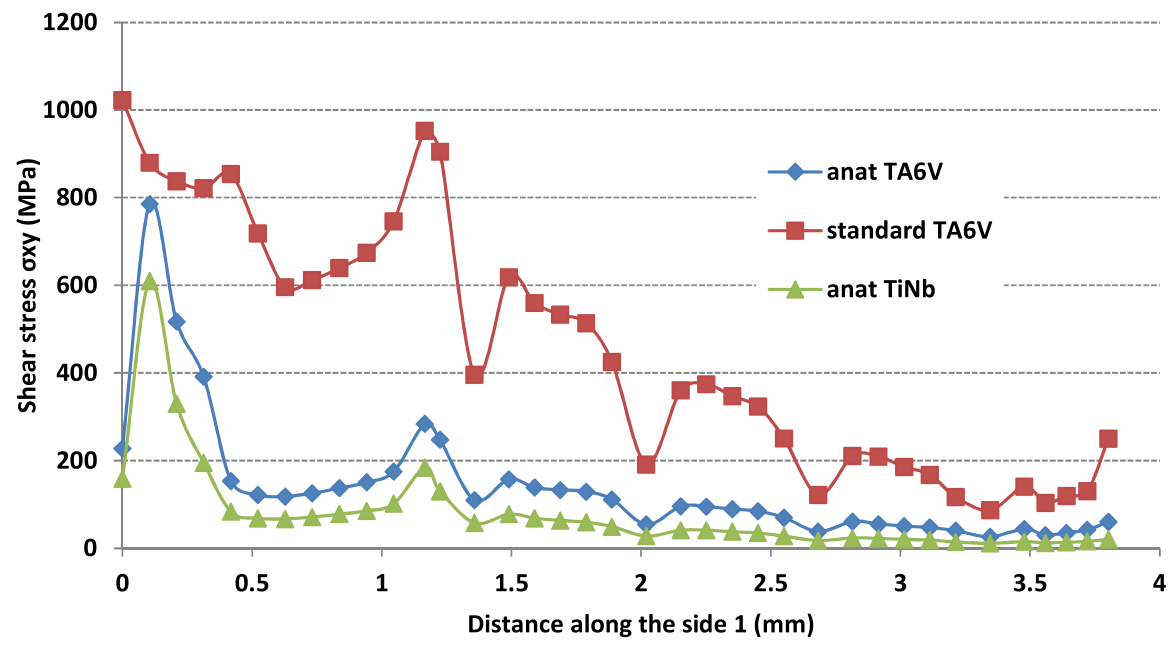

Fig. 17. Representation of the shear stresses in the screw, along the side 1, according to different model configurations.

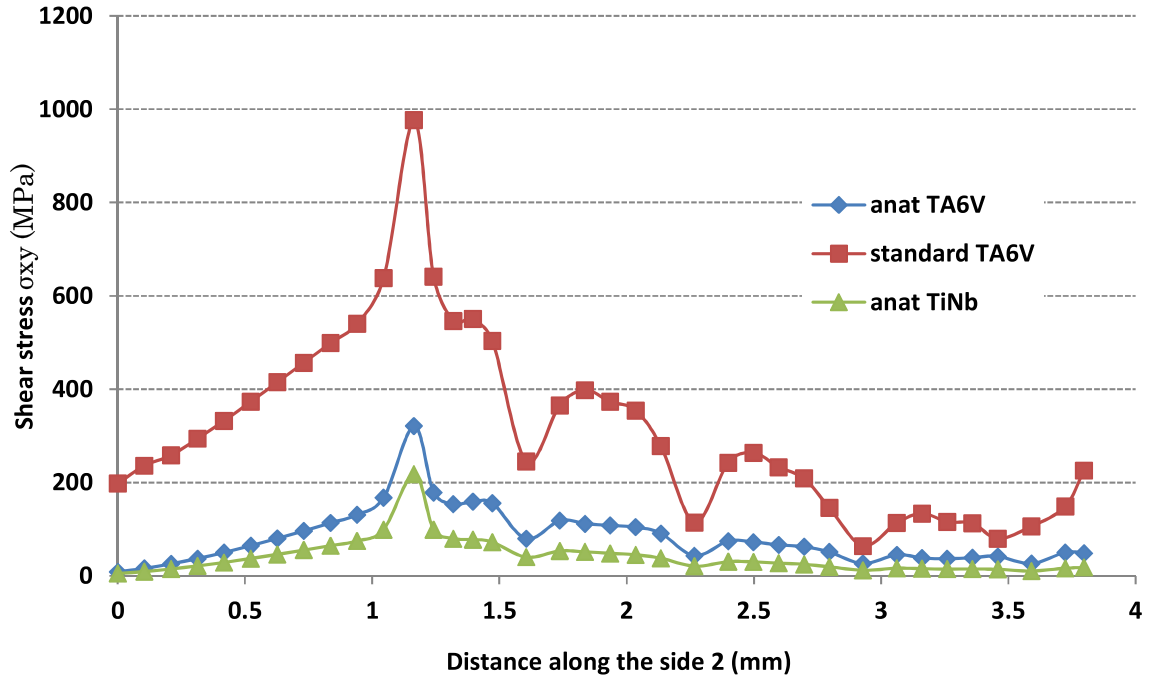

Fig. 18. Representation of the shear stresses in the screw, along the side 2, according to different model configurations.

a) In the placing and tightening of the screw, in the standard model, the bone is stressed by the plastic deformation of the implant, when it is being screwed on the bone surface.

b) When the implant is loaded, preservation of the bone is better when using a custom-made implant the manufacturing of which is made feasible thanks to SLM technology: the general Von Mises stress field, the shear stresses and the stress gap between the screw and the bone are all considerably minimized in the anatomical model compared to the standard case. Concerning the influence of the material, it has been seen that the use of an ultra low Young's modulus alloy also reduces the different stress fields in the bone and in the screw as well as the stress gap between the screw and the bone, thus minimizing stress shielding.

\section{References}

[1] B. Guillaume, Dental implants: a review, Morphologie (2016).

[2] L.R. Williams, K.F. Fan, R.P.B. Custom-made, Custom-made titanium cranioplasty: early and late complications of 151 cranioplasties and review of the literature, Int. J. Oral Maxillofac. Surg. 44 (5) (2015) 599-608.

[3] F.A. Shah, M. Trobos, P. Thomsen, A. Palmquist, Commercially pure titanium (cp-Ti) versus titanium alloy (Ti6Al4V) materials as bone anchored implants-is one truly better than the other ? Mater. Sci. Eng. C 62 (2016) 960-966.

[4] M. Abdel-Hady Gepreel, M. Niinomi, Biocompatibility of Ti-alloys for long-term implantation, J. Mech. Behav. Biomed. Mater. 20 (2013) 407-415.

[5] M. Kaegi, M.L. Buergi, H.A.C. Jacob, H.H. Bereiter, The thrust plate hip prosthesis: a follow-up of 15-20 years with 102 implants, J. Arthroplast. 31 (5) (2016) 1035-1039.

[6] M.I. Ali, Management of compound fracture tibia in children with titanium elastic nails, Apollo Med. 12 (2) (2015) 126-131.

Table 6

Results of the average decrease of the shear stresses in the screw according to different comparisons.

\begin{tabular}{|c|c|c|c|}
\hline $\begin{array}{l}\text { Average diminution of the shear stress in the } \\
\text { screw }\end{array}$ & $\begin{array}{l}\text { Standard Ti-6Al-4V vs. anatomical } \\
\text { Ti-6Al-4V }\end{array}$ & $\begin{array}{l}\text { Anatomical Ti-6Al-4V vs. anatomical } \\
\text { Ti-26Nb }\end{array}$ & $\begin{array}{l}\text { Total: standard Ti-6Al-4V vs. anatomical } \\
\text { Ti-26Nb }\end{array}$ \\
\hline Side 1 & $69 \%$ & $44 \%$ & $83 \%$ \\
\hline Side 2 & $74 \%$ & $49 \%$ & $87 \%$ \\
\hline
\end{tabular}


[7] B.K. Bhuyan, S. Mohan Singh, Titanium elastic nailing in pediatric femoral diaphysea fractures in the age group of 5-16 years-a short term study, J. Clin. Orthop. Trauma 5 (4) (2014) 203-210.

[8] M. Wehmöller, S. Weihe, C. Rasche, P. Scherer, H. Eufinger, CAD/CAM-prefabricated titanium implants for large skull defects-clinical experience with 166 patients from 1994 to 2000, Int. Congr. Ser. 1268 (2004) 667-672

[9] M. Xu, L.-H. Zhang, Y.-Z. Zhang, L.-C. Zhang, C.-Q. He, Y. Wang, P.-F. Tang, Custommade locked plating for acetabular fracture: a pilot study in 24 consecutive cases, Orthopedics 37 (7) (2014) e660-e670.

[10] D. Leordean, C. Dudescu, T. Marcu, P. Berce, N. Balc, Customized implants with specific properties, made by selective laser melting, Rapid Prototyp. J. 21 (1) (2015) 98-104.

[11] S.C. Cox, P. Jamshidi, N.M. Eisenstein, M.A. Webber, H. Hassanin, M.M. Attallah, D.E.T. Shepherd, O. Addison, L.M. Grover, Adding functionality with additive manufacturing: fabrication of titanium-based antibiotic eluting implants, Mater. Sci. Eng. C 64 (2016) 407-415.

[12] N. Otawa, T. Sumida, H. Kitagaki, K. Sasaki, S. Fujibayashi, M. Takemoto, T Nakamura, T. Yamada, Y. Mori, T. Matsushita, Custom-made titanium devices as membranes for bone augmentation in implant treatment: modeling accuracy of titanium products constructed with selective laser melting, J. Cranio-Maxillofac. Surg. 43 (7) (2015) 1289-1295.

[13] X. Li, Y.F. Feng C.T. Wang, G.C. Li, W. Lei, Z.Y. Zhang, L. Wang, Evaluation of biological properties of electron beam melted Ti6Al4V implant with biomimetic coating in vitro and in vivo, PLoS One 7 (12) (2012) 1-12.

[14] O.F. Treatment, Cranial and maxillofacial epithesis treatment on osseointegrated implants: concept and principles, J. Prosthet. Dent. 53 (4) (1985) 552-553.

[15] A.V.H. Greig, S. Jones, C. Haylock, N. Joshi, G. McLellan, P. Clarke, W.N.A. Kirkpatrick Reconstruction of the exenterated orbit with osseointegrated implants, J. Plast. Reconstr. Aesthet. Surg. 63 (10) (2010) 1656-1665.

[16] O. Malard, J. Lanhouet, G. Michel, B. Dreno, F. Espitalier, E. Rio, Pertes de substance étendues de la pyramide nasale: rôle de l'épithèse, Ann. françaises d'Oto-rhinolaryngologie Pathol. Cervico-faciale 132 (2) (2015) 83-87.

[17] T.S. Lee, Standardization of surgical techniques used in facial bone contouring, J. Plast. Reconstr. Aesthet. Surg. 68 (12) (2015) 1694-1700.

[18] R. De Santis, F. Mollica, F. Zarone, L. Ambrosio, L. Nicolais, Biomechanical effects of titanium implants with full arch bridge rehabilitation on a synthetic model of the human jaw, Acta Biomater. 3 (1) (2007) 121-126.

[19] P. Goshulak, S. Samiezadeh, M.S.R. Aziz, H. Bougherara, R. Zdero, E.H. Schemitsch, The biomechanical effect of anteversion and modular neck offset on stress shielding for short-stem versus conventional long-stem hip implants, Med. Eng. Phys. 38 (2016) 232-240.

[20] M.G. Joshi, S.G. Advani, F. Miller, M.H. Santare, Analysis of a femoral hip prosthesis designed to reduce stress shielding. J. Biomech. 33 (2000) 1655-1662.

[21] Y. Li, C. Yang, H. Zhao, S. Qu, X. Li, Y. Li, New Developments of Ti-Based Alloys for Biomedical Applications, Materials (Basel) 7 (2014) 1709-1800.

[22] W. Elmay, F. Prima, T. Gloriant, B. Bolle, Y. Zhong, E. Patoor, P. Laheurte, Effects of thermomechanical process on the microstructure and mechanical properties of a fully martensitic titanium-based biomedical alloy, J. Mech. Behav. Biomed. Mater. 18 (2013) 47-56.

[23] B. Piotrowski, A.A. Baptista, E. Patoor, P. Bravetti, A. Eberhardt, P. Laheurte, Interaction of bone-dental implant with new ultra low modulus alloy using a numerical approach, Mater. Sci. Eng. C 38 (1) (2014) 151-160.

[24] Y. Handan, Evaluation of stress distributions occurring on zirconia and titanium implant-supported prostheses: a three-dimensional fi nite element analysis, J. Prosthet. Dent. (03) (2014) 1-10.
[25] H. Eduardo, D. Bordin, A.A. Del, B. Cury, W. José, F. Faot, The role of prosthetic abutment material on the stress distribution in a maxillary single implant-supported fi xed prosthesis, Mater. Sci. Eng. C 65 (2016) 90-96.

[26] M. Niinomi, M. Nakai, J. Hieda, Development of new metallic alloys for biomedical applications, Acta Biomater. 8 (11) (2012) 3888-3903.

[27] A. Cremasco, A.D. Messias, A.R. Esposito, E.A. de R. Duek, R. Caram, Effects of alloying elements on the cytotoxic response of titanium alloys, Mater. Sci. Eng. C 31 (5) (2011 Jul.) 833-839.

[28] M. Metikoš-Huković, A. Kwokal, J. Piljac, The influence of niobium and vanadium on passivity of titanium-based implants in physiological solution, Biomaterials 24 (21) (Sep. 2003) 3765-3775.

[29] Y. Bai, S.J. Li, F. Prima, Y.L. Hao, R. Yang, Electrochemical corrosion behavior of Ti$24 \mathrm{Nb}-4 \mathrm{Zr}-8 \mathrm{Sn}$ alloy in a simulated physiological environment, Appl. Surf. Sci. 258 (8) (Feb. 2012) 4035-4040.

[30] R.E. McMahon, J. Ma, S.V. Verkhoturov, D. Munoz-Pinto, I. Karaman, F. Rubitschek, H.J. Maier, M.S. Hahn, A comparative study of the cytotoxicity and corrosion resistance of nickel-titanium and titanium-niobium shape memory alloys, Acta Biomater. 8 (7) (Jul. 2012) 2863-2870.

[31] E. Eisenbarth, D. Velten, M. Müller, R. Thull, J. Breme, Biocompatibility of beta-stabilizing elements of titanium alloys, Biomaterials 25 (26) (Nov. 2004) 5705-5713.

[32] M. Fischer, D. Joguet, G. Robin, L. Peltier, P. Laheurte, In situ elaboration of a binary Ti-26Nb alloy by selective laser melting of elemental titanium and niobium mixed powders, Mater. Sci. Eng. C 62 (2016) 852-859.

[33] L.-M. Favot, V. Berry-Kromer, M. Haboussi, F. Thiebaud, T. Ben Zineb, Numerical study of the influence of material parameters on the mechanical behaviour of a rehabilitated edentulous mandible, J. Dent. 2 (42) (2014) 297.

[34] F.R. Verri, V. Eduardo, D.S. Batista, J. Ferreira, S. Jr, D. Augusto, D.F. Almeida, E.P. Pellizzer, Effect of crown-to-implant ratio on peri-implant stress: a finite element analysis, Mater. Sci. Eng. C 45 (2014) 234-240.

[35] J.F. Santiago, F.R. Verri, D.A.D.F. Almeida, V.E. De Souza Batista, C.A.A. Lemos, E.P. Pellizzer, Finite element analysis on influence of implant surface treatments, connection and bone types, Mater. Sci. Eng. C 63 (2016) 292-300.

[36] M.A. Darwich, M.H. Albogha, A. Abdelmajeed, K. Darwich, Assessment of the biomechanical performance of 5 plating techniques in fixation of mandibular subcondylar fracture using finite element analysis, J. Oral Maxillofac. Surg. 74 (4) (2016) 794e1-794e8.

[37] S.F. Huang, L.J. Lo, C.L. Lin, Biomechanical optimization of a custom-made positioning and fixing bone plate for Le Fort I osteotomy by finite element analysis, Comput. Biol. Med. 68 (2016) 49-56.

[38] V. Tuninetti, G. Gilles, O. Milis, T. Pardoen, A.M. Habraken, Anisotropy and tension-compression asymmetry modeling of the room temperature plastic response of Ti-6Al-4V, Int. J. Plast. 67 (2015) 53-68.

[39] S. Bernard, Q. Grimal, P. Laugier, Accurate measurement of cortical bone elasticity tensor with resonant ultrasound spectroscopy, J. Mech. Behav. Biomed. Mater. 18 (2013) 12-19.

[40] C.H. Turner, J. Rho, Y. Takano, T.Y. Tsui, G.M. Pharr, The elastic properties of trabecular and cortical bone tissues are similar: results from two microscopic measurement techniques, J. Biomech. 32 (4) (1999) 437-441.

[41] M. Prot, T.J. Cloete, D. Saletti, S. Laporte, The behavior of cancellous bone from quasistatic to dynamic strain rates with emphasis on the intermediate regime, J. Biomech. 49 (7) (2016) 1050-1057. 